\title{
Risks and Opportunities of Reforms Putting Primary Care in the Driver's Seat

\author{
Comment on "Governance, Government, and the Search for New Provider Models"
}

\author{
Monica Andersson Bäck*
}

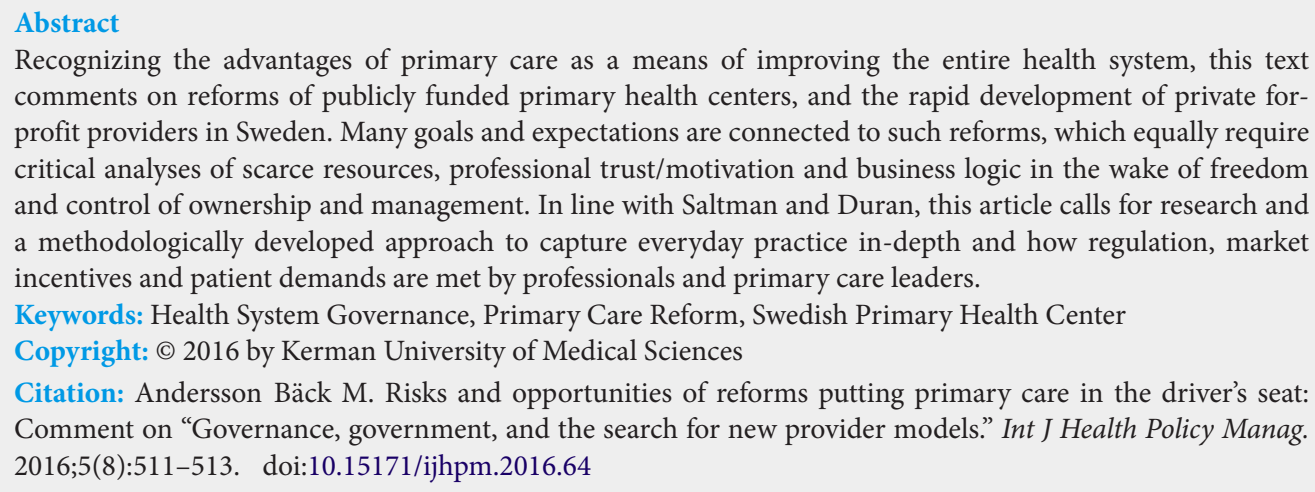

\section{Article History:}

Received: 30 March 2016

Accepted: 21 May 2016

ePublished: 24 May 2016
*Correspondence to:

Monica Andersson Bäck

Email: monica.andersson.back@gu.se
$\mathrm{I}$ $\mathrm{n}$ a recent debate article "Governance, Government, and the Search for New Provider Models," Saltman and Duran reflect groundbreaking processes in reforming tax-based health and their complexity in two European countries. ${ }^{1}$ One of the examples springs from Swedish primary care and discusses governments' strategies of steering providers based on market incentives and management structures encouraging efficient performance and citizens' possibility of enlisting with a primary care provider of their choice. ${ }^{1}$ Their article is interesting in several ways, covering a substantial change in favor of primary care centers. The rapid development of new ways to operate primary care and new private actors implies a break with traditionally public provision and organization, which has dominated Swedish healthcare the last 50 years. It is a controversial change that has received much attention, both in and outside Sweden., ${ }^{2,3}$ However, despite their insightful observations, I argue herein that further key dimensions need to be explored in order to capture consequences, intended as well as unintended, and to understand the dynamics of complexity in the case in focus.

The shift in governance, since 2007, aiming for competition and choice in primary care, was established in 2010 following a change of the Health and Medical Service Act. Freedom of enlisting encourages citizens to choose their primary health center, among public and private providers, and freedom of establishment makes it possible for private for-profit actors to establish primary care centers and compete for patients. ${ }^{2}$ It means that primary care centers no longer have a guaranteed population to serve, based on catchment areas, but should work on access and responsiveness to attract and maintain enlisted patients ${ }^{2}$ as well as work on their own management of high quality. The purpose of this commentary is to contribute to the discussion of new provider models and practice in primary care by further uncovering embedded complexity and how it can be studied.

Swedish Primary Care Centers, Goals and Providers The Swedish health system is often cited because of its very good health outcomes, ie, low mortality of heart infarctions, breast and colorectal cancer, comparatively few infant deaths, few methicillin-resistant Staphylococcus aureus (MRSA) infections together with a satisfactory level of 'avoidable' deaths and a broad range of service provided, at the same time as its persistent problems continue to surprise: poor access, and long waiting times. ${ }^{4}$ Hindering bureaucracy, high pressure on emergency care and low patient- and service-orientation are other problems addressed. ${ }^{4}$ Thus, new governance is aiming for the empowerment and autonomy of caretakers, factors shown to improve patient compliance and health status. ${ }^{2}$ Putting primary care in the driver's seat of a healthcare system entails efforts to obtain its fundamental pillars: first-contact care; continuity of care over time; comprehensiveness, or concern for the entire patient rather than a one-organ system; and coordination with other parts of the health system. ${ }^{5,6}$ In Sweden, about 10 million citizens are covered by approximately 1200 public and private primary care centers, comprising $10 \%$ of the overall healthcare budget. ${ }^{3}$ The reforms are applied to a community model for primary care typical for Sweden since the 1970s, but rather unique in an international perspective. ${ }^{2}$ The Swedish primary care center, in contrast with most other the Organization for Economic Co-operation and Development (OECD) countries, employs a multidisciplinary workforce with some 4-10 general practitioners (GPs) working together with several other professionals, such as district nurses, physical therapists, social workers, occupational therapists, psychologists 
and nurses specializing in diabetes and asthma/chronic obstructive pulmonary disease (COPD) and other chronical symptoms. ${ }^{3}$ Internationally, primary care is usually provided by single or small groups of private GPs. ${ }^{5}$ But the trend in publicly funded primary care is apparently moving in the direction of publicly salaried multidisciplinary employees. ${ }^{6}$ With their multidisciplinary workforce, primary care centers are well-equipped to provide a large range of services, many of which are directly referred to specialized care in other systems. Primary care in the driver's seat is considered to 'free' hospitals from patients with less serious problems not needing specialized resources, guiding the patient to the right level within the health system, without a formal function as gate-keeper. ${ }^{6,7}$

\section{Scarce Resources: Shortage of General Practitioners}

Nonetheless, overall resources have not been allocated accordingly, with a great emphasis on specialized healthcare and hospital care, and with only $17 \%$ left for primary care. ${ }^{3}$ The shortage of GPs is furthermore considered alarming. With only $16 \%$ of specialized doctors trained for primary care, ${ }^{3}$ Sweden has a lower proportion of GPs than most other comparable countries. ${ }^{8}$ Physician density varies among Swedish counties, and most GP as well as private primary care centers are found in the three largest cities, while northern regions and individual counties struggle to fill GP vacancies. ${ }^{7}$ Many GP positions are held by physicians undergoing their mandatory practical training, substitutes and physicians from manpower agencies or doctors trained outside of Sweden. This has been hard on budgets and patient continuity. ${ }^{7}$ Some explanations are a high level of retirement among GPs and medical graduates avoiding primary care, as well as adverse workloads and working conditions which lead many doctors to prefer part-time.,

Patients want to follow their doctors, if possible, even when they change workplaces. However, with the new provider model it is difficult to develop an individual-physician relationship, with some few exceptions. This is contradictory, as continuity might be a major reason why patients make a choice. ${ }^{7}$ Yet, the new governance has been arranged based on experience from the failure of a previous Swedish reform involving registration with one family doctor. ${ }^{1}$ With the new model, providers are free to manage and design working conditions, which might be a means to attract physicians with higher salaries, more autonomy, more time to meet the patients, better work environments, and freedom from unrewarding administrative tasks. One observation is that care centers managed by physicians tend to have sufficient medical manning and subsequently better financial results. Another is that several public care centers suffer from insufficient revenues with the risk of closing down. ${ }^{7}$ Apparently, the new governance means that competition is not solely a question of public listing, but also one of enhancing the attraction of primary care in the eyes of GPs and specialized nurses, ie, scarce manning resources. It is also about winning people's trust and promoting the legitimacy of always seeking primary service for non-life-threatening health problems.

Trust, Motivation and Business Logic

Public ownership still dominates but with a new provider model, the number of private primary care providers has increased substantially $(+80 \%)$ and almost all new providers are private and profit-driven companies. However, the proportion of private primary care units varies substantially across counties/regions. ${ }^{7}$ Areas that have experimented with new models early have a significantly higher share of private providers today, eg, in Stockholm more than $50 \%$ of primary care centers are privately owned, whereas only a few private units exist in the northern part of Sweden. ${ }^{2,7}$ Inequity is not considered a problem, but some observations are made that new providers seem to avoid areas with complex care needs. ${ }^{9}$ The aim to get more and stronger non-profit actors is far from being materialized ${ }^{1,2}$ instead most providers are profitdriven companies with several of the big actors having foreign owners. ${ }^{10}$ Consequently, the entire system and its dynamics tend to be under transition. Some have debated risks of a new oligopoly with private providers acting monopolistically. ${ }^{2} \mathrm{~A}$ subsequent question is whether, when the healthcare system imitates private business, we can rely on professionals and the public-service ethos to deliver good quality on ethical grounds? And what about primary care centers in the hands of business, sometimes foreign and sometimes owned by risk-taking funding groups, aiming for good returns on their investments? Furthermore, choice reform has shown to contrast efficient coordination of health and social care for elderly with greater needs, ${ }^{11}$ and how should that be tackled in the future?

As a result of decentralized governance in Sweden, each region can design its regulations and financial incentives and achieve various practices and outcomes. This entails that it is more difficult to aggregate national information on contracted service and practice and to make comparisons among models and practices. ${ }^{2,3}$ This obstacle is salient, as providers generally respond as expected to incentives, namely by offering more and more often services that provide high compensation, and regrettably including services that are of marginal value, useless, or even harmful. ${ }^{12}$ The long-term effects in terms of quality improvements, innovativeness, problem-solving and resistance are hard to conclude, however, owing to the lack of evidence based on systematic and robustly designed research. ${ }^{12}$

Governance based on incentives also risks unintended consequences such as gaming, playing, resistance, social and group norms and other ways of distorting data, as measuring becomes more important than producing quality. ${ }^{12}$ Lack of autonomy and feelings of decreased motivation among professionals might be other consequences, ${ }^{10}$ while prioritization of easier symptoms and problems at the expense of the chronically ill and elderly people with multiple problems is an additional consequence of focusing on patients' choices and demands. ${ }^{5}$

With new governance comes higher demands on governments to ensure the quality of healthcare for patients and citizens, and to provide systems that allow transparency, ${ }^{2}$ not least in connection with private for-profit providers. The national government's responsibility is exercised through broadlywritten 'framework' legislation as well as through a number of national agencies and ongoing statistical surveys for assessing service quality and outcomes. ${ }^{3}$ The overall intention is to NOT limit competition, which is why Swedish legislation 
includes no restrictions on the type of private entity that could own and/or operate new primary care practice, or any other kinds of limitations of governance. ${ }^{7}$ Considered highly controversial, an ongoing debate questions why the welfare service sector in Sweden is less regulated than in many other countries. This is expressed as a trade-off between regulation and control, on the one hand, and capital and innovative care, on the other. ${ }^{13}$

\section{Capturing Practice and Outcome}

Implementing major structural changes and market incentives has proven to be difficult, as different levels of the health system are usually loosely coupled to each other. At the micro level, flexibility is necessary to handle local conditions and adapt to needs. ${ }^{1}$ One negative consequence is that organizations can take on formal decisions from central levels to satisfy demands for change, without letting changes have a real impact on concrete activities. In knowledge-intensive activities such as healthcare, it is common that professionals operating independently shut themselves off from central requirements that are not perceived as meaningful. Accordingly, the units fulfill formal requirements and reporting, but the work itself is not affected. ${ }^{12}$ When studying implementation empirically, it is, therefore, important to pay attention to the local organizational context, in terms of factors that can both prevent and facilitate a real change. Expressed in terms of Saltman and Duran, well-functioning governance is formed at the macro level, but in the end what is crucial is how regulation and incentives are understood and manifested in daily work. ${ }^{1}$ Capturing everyday practice is easier said than done, however. There is little research about what is happening in new primary care centers after the reform, and qualitative approaches aiming for thick descriptions are needed. A Swedish case study of that kind is currently underway, focusing on primary care centers with varying forms of ownership, all of which are regarded as successful. In order to catch everyday practice and how regulation, market incentives and patient demands are met by professionals and primary care leaders, interviews as well as observations are being intertwined with studies of registries and documents. Early findings explore providers' management and how professionals in primary care centers engage differently with financial incentives, expressed as 'What we do is the same but how we do it is different.' ${ }^{14}$

The new model places the Swedish health system on the horns of a dilemma: how to simultaneously mobilize capital, innovation and cost-efficient service, while care-users and citizens experience freedom of choice, satisfaction, and empowerment (that their needs, demands and taxes are properly considered), and at the same time motivate providers toward efficient care of high quality (neither too much nor too little) based on ethical behavior and job satisfaction. The list of goals and expectations is long, and contradictions and tradeoffs once again confirm the complex nature of healthcare.

\section{Acknowledgments}

This comment draws on current research Log No. 130343 funded by AFA Försäkringar, Stockholm, Sweden, who the author wishes to thank, as well as colleagues in the Sofia Kjellström, Gunilla Avby, and Boel Andersson Gäre research group.

\section{Ethical issues}

Not applicable.

\section{Competing interests}

Author declares that she has no competing interests.

Author's contribution

$M A B$ is the single author of the paper.

\section{References}

1. Saltman RB, Duran A. Governance, government, and the search for new provider models. Int $J$ Health Policy Manag. 2016;5(1):33-42. doi:10.15171/ijhpm.2015.198

2. Anell A. Choice and privatisation in Swedish primary care. Health Economics, Policy and Law. 2011;6:549-569. doi:10.1017/ s1744133110000216

3. Anell A, Glenngard AH, Merkur SM. Sweden: Health system review. Health Syst Transit. 2012;14(5):1-159.

4. Health Consumer Powerhouse. Outcomes in $\mathrm{EHCl}$; Report 2015.

5. Bodenheimer T, Pham HH. Primary care: current problems and proposed solutions. Health Aff (Millwood). 2010;29(5):799-805. doi:10.1377/hlthaff.2010.0026

6. Saltman RB, Rico A, Boerma W, eds. Primary Care in the Driver's Seat? Organizational Reform in European Primary Care. Maidenhead, UK: McGraw-Hill Education; 2006.

7. Swedish Competition Authority. Establishment and competition among primary care centers - about quality driven competition and financial conditions; 2014.

8. Paris V, Devaux M, Wei L. Health Systems institutional characteristics: a survey of 29 OECD countries. OECD Health Working Papers. OECD Publishing; 2010.

9. Isaksson D, Blomqvist $P$, Winblad U. Free establishment of primary health care providers: effects on geographical equity. BMC Health Serv Res. 2016;16:28. doi:10.1186/s12913-0161259-z

10. Andersson Bäck M, Calltorp J, Saltman RB. Privatization in Swedish health care. Working paper, Swedish Forum on Health Policy. Stockholm; 2013.

11. Andersson Bäck M, Calltorp J. The Norrtaelje model: a unique model for integrated health and social care in Sweden. Int $J$ Integr Care. 2015;15:e016. doi:10.5334/ijic.2244

12. Bevan $G$, Hood $C$. What's measured is what matters: targets and gaming in the English public health care system. Public Adm. 2006;84(3):517-538. doi:10.1111/j.1467-9299.2006.00600.x

13. Anell A. The Public-Private Pendulum-Patient Choice and Equity in Sweden. N Engl J Med. 2015;372(1):1-4. doi:10.1056/ nejmp1411430

14. Kjellström S, Avby G, Andersson Bäck M. Financial Incentives \& Motivation. The International Forum on Quality and Safety in Healthcare, Improvement Science Symposium; April 12-15, 2016 Gothenburg. 